\title{
Phytohormone treatment induces generation of cryptic peptides with antimicrobial activity in the Moss Physcomitrella patens
}

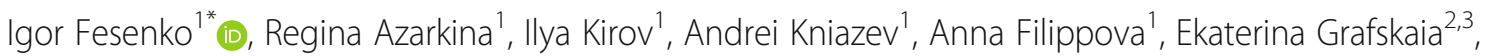
Vassili Lazarev²,3 Victor Zgoda ${ }^{4}$, Ivan Butenko², Olga Bukato², Irina Lyapina ${ }^{1}$, Dmitry Nazarenko ${ }^{5}$, Sergey Elansky ${ }^{6}$, Anna Mamaeva', Vadim Ivanov ${ }^{1}$ and Vadim Govorun ${ }^{2}$

\begin{abstract}
Background: Cryptic peptides (cryptides) are small bioactive molecules generated via degradation of functionally active proteins. Only a few examples of plant cryptides playing an important role in plant defense have been reported to date, hence our knowledge about cryptic signals hidden in protein structure remains very limited. Moreover, little is known about how stress conditions influence the size of endogenous peptide pools, and which of these peptides themselves have biological functions is currently unclear.

Results: Here, we used mass spectrometry to comprehensively analyze the endogenous peptide pools generated from functionally active proteins inside the cell and in the secretome from the model plant Physcomitrella patens. Overall, we identified approximately 4,000 intracellular and approximately 500 secreted peptides. We found that the secretome and cellular peptidomes did not show significant overlap and that respective protein precursors have very different protein degradation patterns. We showed that treatment with the plant stress hormone methyl jasmonate induced specific proteolysis of new functional proteins and the release of bioactive peptides having an antimicrobial activity and capable to elicit the expression of plant defense genes. Finally, we showed that the inhibition of protease activity during methyl jasmonate treatment decreased the secretome antimicrobial potential, suggesting an important role of peptides released from proteins in immune response.

Conclusions: Using mass-spectrometry, in vitro experiments and bioinformatics analysis, we found that methyl jasmonate acid induces significant changes in the peptide pools and that some of the resulting peptides possess antimicrobial and regulatory activities. Moreover, our study provides a list of peptides for further study of potential plant cryptides.
\end{abstract}

Keywords: LC-MS/MS, Peptidome, Plant immunity, Physcomitrella patens, Secretome, Phytohormones

\footnotetext{
* Correspondence: fesigor@gmail.com

${ }^{1}$ Laboratory of Proteomics, Shemyakin and Ovchinnikov Institute of

Bioorganic Chemistry, Russian Academy of Sciences, Moscow, Russia

Full list of author information is available at the end of the article
}

(c) The Author(s). 2019 Open Access This article is distributed under the terms of the Creative Commons Attribution 4.0 International License (http://creativecommons.org/licenses/by/4.0/), which permits unrestricted use, distribution, and reproduction in any medium, provided you give appropriate credit to the original author(s) and the source, provide a link to the Creative Commons license, and indicate if changes were made. The Creative Commons Public Domain Dedication waiver (http://creativecommons.org/publicdomain/zero/1.0/) applies to the data made available in this article, unless otherwise stated. 


\section{Background}

Peptides play an important role in growth and development, stress-induced responses and defense mechanisms [1-4]. As such, the peptidome can be considered the "dark matter" of the proteome: it includes thousands of potentially active molecules whose functions are not yet fully understood. Most bioactive plant peptides analyzed to date are generated via processing of inactive protein precursors. However, recent studies have shown that bioactive peptides can also be directly translated from short open reading frames $[1,5,6]$. In addition, a substantial part of plant cell peptidome comprises the proteolytic degradome, i.e., peptides generated via degradation of functional proteins [7].

While degradome peptides are often ignored as merely breakdown products resulting from regulation of active proteins, there is increasing evidence that peptides of the proteolytic degradome can be biologically functional. A number of cryptides, bioactive peptides hidden in protein structures, have been described in human [8-10]. Among plant cryptides, inceptin is a fragment of chloroplast ATP-synthase from Chinese cowpea (Vigna unguiculata), GmSubPep and GmPep914 are fragments of subtilisin-like protease in soybean (Glycine max) and CAPE-1 is a fragment of an active PR-1 tomato protein [11-14]. Each of these plant peptides plays a role in plant defense as an elicitor molecule.

Of special interest are bioactive peptides generated from functional proteins under stress conditions or hormone treatment. Hormone signaling in response to pathogen invasion can lead to the activation of protective mechanisms in plants. Phytohormones induce the proteolysis of certain proteins, thereby influencing the peptidome landscape [14-17]. This proteolysis has also been reported to generate peptides with biological activity. For instance, methyl jasmonate (MeJA) causes degradation of the tomato PR-1 protein and secretion of the peptide CAPE1, which regulates plant defense responses and has insecticidal activities [14, 15]. These results indicate that the degradome peptides represent more than simply a reflection of the breakdown of the proteome. However, although the effects of hormones on the intact proteome have been catalogued in several tissues, species and conditions, the converse impact of stress hormones on peptidogenesis itself in plant cells has not yet been assessed $[18,19]$. Some peptides are secreted into the extracellular space, contributing to the plant cell secretome [20, 21]. For instance, defensins are secreted plant peptides that have antimicrobial activity [22-26]. Only a few secreted plant peptides have been well studied, such as CLE (CLAVATA3 [CLV3]/ENDOSPERM SURROUNDING REGION [ESR]), CRP (cysteine-rich) and PSK (phytosulfokine) [27-35]. Since no comprehensive analysis of peptides in the plant secretome has been conducted to date, our knowledge of their functions and origins remains limited.

We previously performed a systematic study of peptidogenesis in gametophores, protonemata and protoplasts of $P$. patens and found that the composition of the peptide pools (a set of all identified endogenous peptides) strongly differs between these cell types [7]. According to the recent studies, moss secretome contains a number of proteins, including different types of proteases and stress-responsive proteins [36, 37]. However, their role in the extracellular peptide pools formation remains to be elucidated. The aim of the present study was to carry out comprehensive analysis of the peptides of the $P$. patens secretome and to examine the influence of stress hormones on the cell peptidome and secretome. Using mass-spectrometry analysis, we analyzed pools of native peptides extracted from cells and the culture medium of the moss $P$. patens before and after treatment with the phytohormone MeJA. Hormone treatment led to a dramatic increase in the sizes of peptide pools both within the cell and in the secretome. We also observed an increase in the proteolysis rate of precursors under MeJA treatment, as well as hormonespecific degradation of new functional proteins. Moreover, the protein degradation patterns significantly differed between the cell and the secretome, suggesting that distinct types of proteolytic enzymes might be located in these compartments. Using in silico and in vivo analysis of the identified peptides from functionally active proteins upon treatment with MeJA, we detected antimicrobial activity in a number of the generated peptides. We identified the cryptic peptide, which has the highest predicted antimicrobial potential in the secretome, influenced the transcription of pathogenesis-related genes in a time-dependent manner. Therefore, the plant peptidomes include a number of bioactive peptides originating from functional proteins whose roles were previously underestimated.

\section{Results \\ Methyl jasmonate induces changes in both intracellular and secretome peptidomes}

Physcomitrella patens responds to MeJA exogenous treatment by growth inhibition and induction of pathogenesis-related genes [38-40]. To determine whether this stress hormone influences the plant peptidome, we identified intracellular and extracellular endogenous peptides in the control and MeJA-treated moss protonema cells and secretome samples (Additional file 1: Figure S1). To check if the process of sample preparation influences the peptidome composition, we added eleven synthetic peptides (RT peptides), having a broad range of retention time to original samples (cell homogenate or culture media in case of secretome). All RT peptides were 
then identified both in the secretome and the cell samples by Multiple Reaction Monitoring (MRM) experiment, demonstrating a similar peptide recovery in both extraction procedures (Additional file 2: Figure S2, Additional file 3: Table S1).

We examined endogenous peptides extracted from $P$. patens protonema cells treated with $0.4 \mathrm{mM}$ MeJA. Taking into account the heterogeneity of peptide pools, for further analysis peptides identified in at least two biological repeats were selected. Overall, 4533 endogenous peptides belonging to 1000 protein precursors have been identified (Fig. 1a, b). We identified about $45 \%$ peptides as C-terminal peptides, defined as starting within 50 amino acid of the C-terminus of the protein. While a significant portion of the peptide pool was identical between control and treated cells, MeJA resulted in the generation of 245 (about $5.5 \%$ of total peptides) additional peptides; 67 $(27 \%)$ of these peptides were generated from new precursors in MeJA-treated cells (Additional file 4: Table S2). The distribution of peptide intensities showed a high correlation between MeJA-treated and control sample (Pearson $\mathrm{r}=0.68, p$-value 5.4e-284; Additional file 5: Figure S3). Most peptides in the cell peptidome originated from proteins involved in photosynthesis, the Calvin cycle, glycolysis and sucrose biosynthesis (Additional file 6: Figure S4). MeJA-treated samples had more identified peptides per protein compared with the control.

We then used mass-spectrometry analysis to identify peptides in the protonema culture medium and to explore the impact of MeJA on the cell secretome. We detected 482 peptides in protonema culture medium derived from 114 proteins in at least two biological repeats (Additional file 7: Table S3). According to GO analysis, most of the precursors represent photosystem I and extracellular or extrinsic membrane proteins, such as alpha-expansin (EXPA6), pectin methylesterase and others (Fig. 1c). We identified 11 additional unique peptides after short-term treatment $(1 \mathrm{~h})$ of the protonemata with $0.4 \mathrm{mM} \mathrm{MeJA} \mathrm{(Fig.} \mathrm{1d).} \mathrm{The} \mathrm{precursors} \mathrm{of}$ plant bioactive peptides and hormones are often small

\section{A intracellular peptides}

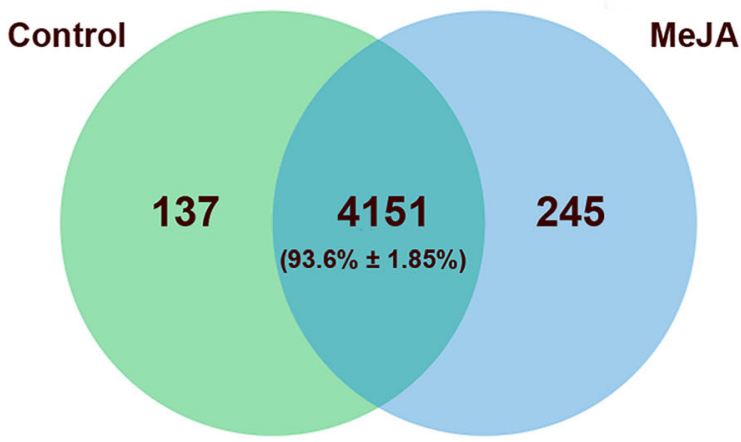

C

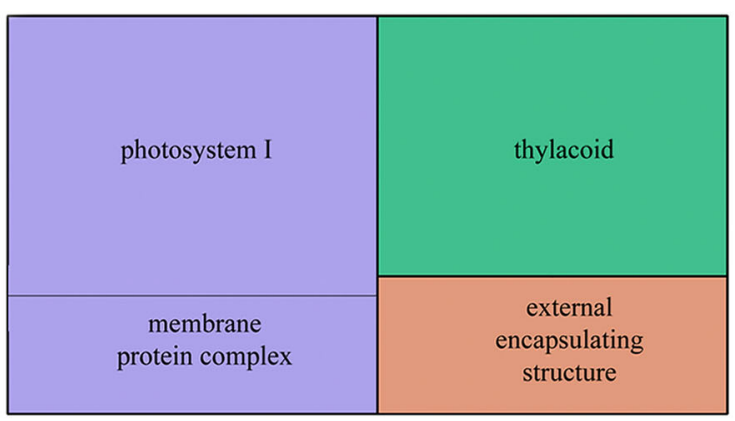

B

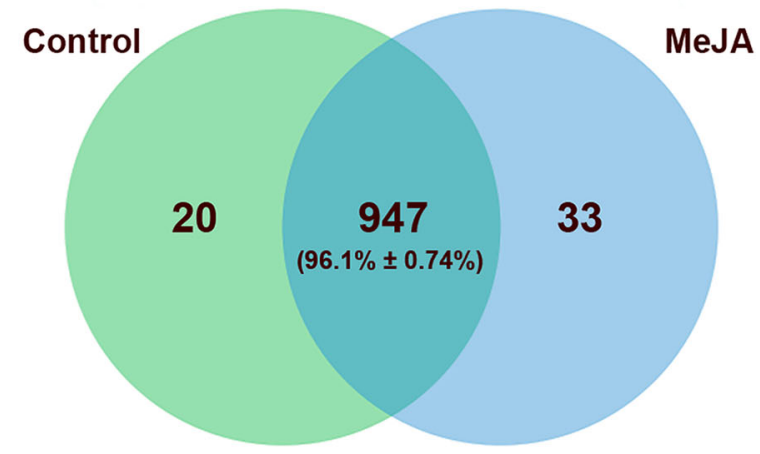

D extracellular peptides

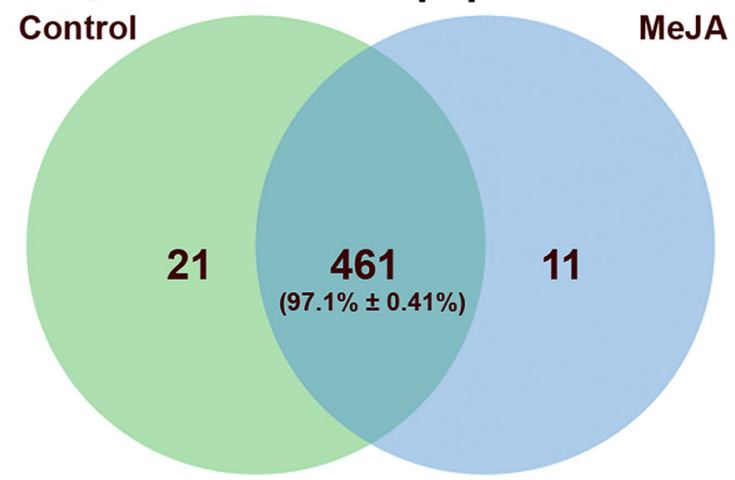

Fig. 1 The comparison among endogenous peptides and their precursors between control and MeJA-treated samples. Venn diagram showing a comparison among endogenous peptides (a) and their precursors (b) between control and MeJA-treated protonema cells ( $n=3$ independent biological repeats). c TreeMap showing GO enrichment terms ("Cellular component") in a set of secretome peptide precursor proteins ( $p$-value<0.05). The size of each square corresponds to the -log10(P-value). $\mathbf{d}$ Venn diagram showing a comparison among secreted peptides from protonemata treated with MeJA and control samples ( $n=3$ independent biological repeats). The mean percentage with standard deviation for common peptides is shown 
proteins without predicted functions [1]. In the moss secretome, we also identified peptides originated from thirty-nine small $(<200 \mathrm{aa})$ proteins. Three of them were predicted proteins, which gave rise to peptides whose abundance, increased upon MeJA treatment. The possible function of these peptides remains to be elucidated.

\section{Changes in protein degradation patterns under MeJA treatment}

We compared the protein degradation patterns (PDPs) of precursors identified in both control and MeJAtreated samples. Taking into account the possibility of generating endogenous peptides from the same parts of proteins that slightly differ from each other (peptide ladders), we used a $10 \%$ window for precursor length to estimate PDPs. We found that PDPs were quite similar between MeJA-treated and control samples for the secretome as well as the intracellular peptidome (Fig. 2).
We estimated that the fraction of peptides originating from precursors unique to MeJA-treated samples represents less than half of all unique peptides. In other words, hormone-induced stress increased the proteolysis rates of proteins from which peptides are normally formed in the moss peptidome, as well as new protein precursors (Additional file 4: Table S2, Additional file 7: Table S3). Whether this process results from a general disturbance of proteolytic activity or whether the peptides are generated as a target response to stress is currently unknown.

Analyzing shifts in the amino acid compositions of peptides can shed light on their biochemical properties and possible functions. We therefore compared amino acid frequencies (AAFs) in the secretome, cellular peptidome and a set of peptides artificially generated from protein regions not present in the mass-spectrometry data. No significant differences were found between the

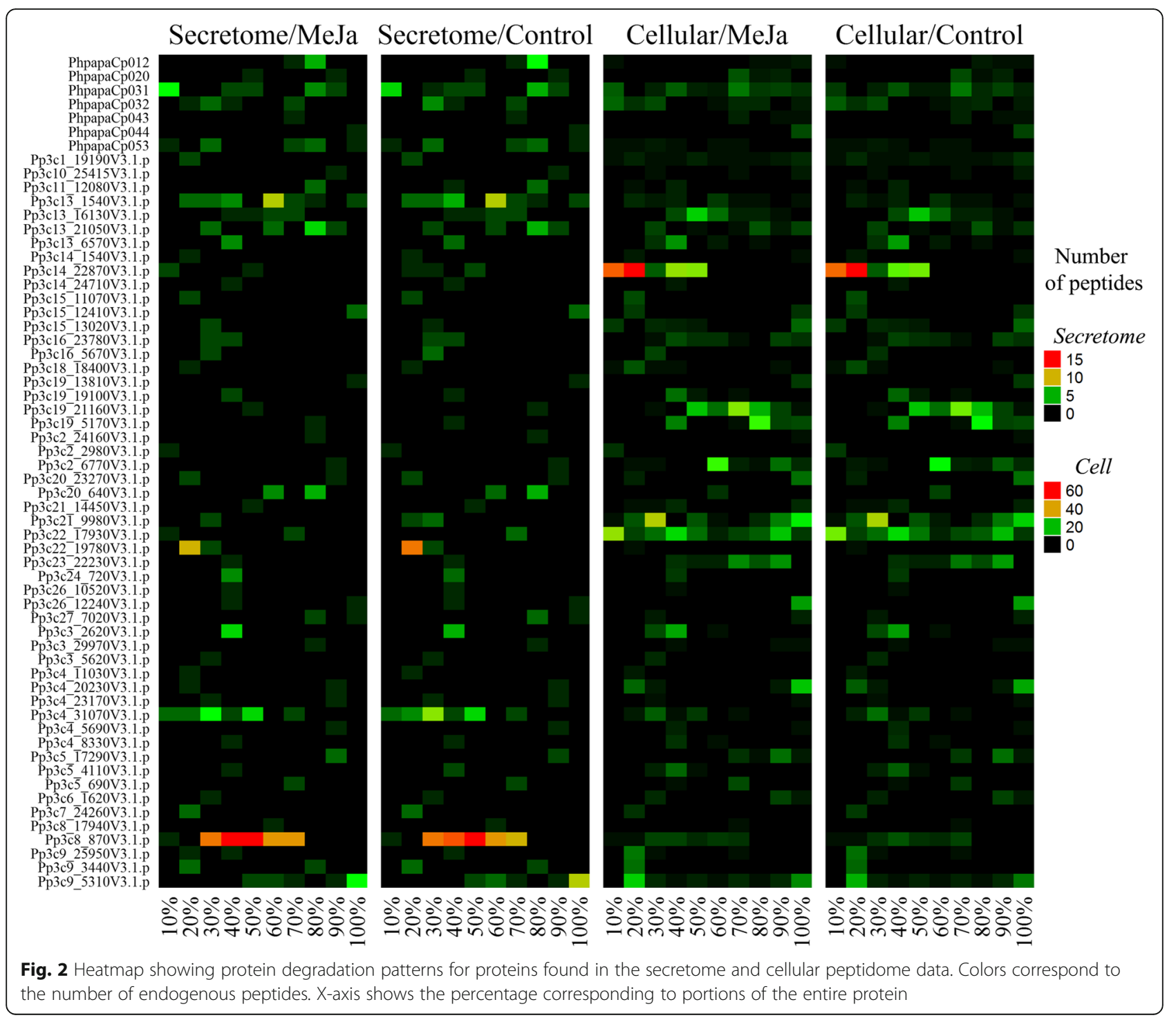



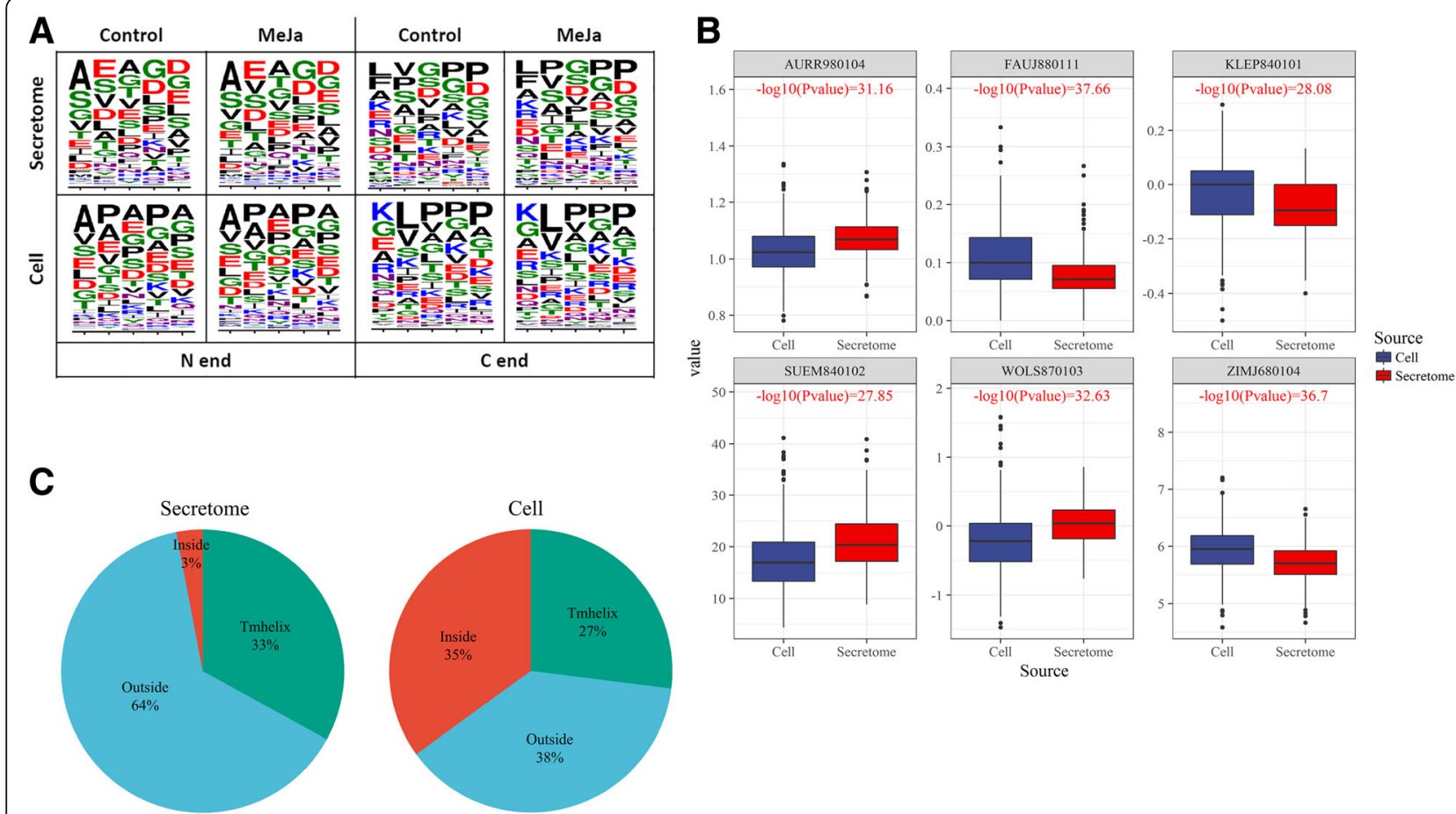

Fig. 3 Physicochemical properties of the intracellular and secreted peptides. a Sequence logos of the five N-and C-terminal amino acids of peptides from the secretome and cell. Colors correspond to amino acid chemical properties (green, purple, blue, red and black correspond to polar, neutral, basic, acidic and hydrophobic properties, respectively). $\mathbf{b}$ Boxplots showing differences in mean values of six the most significant "sigAA" indexes (P-value differences < e-25). KLEP840101: Net charge [83], FAUJ880111: Positive charge [84], ZIMJ680104: Isoelectric point [85], WOLS870103: Principal property value z3 [86], AURR980104: Normalized positional residue frequency at helix termini N' [87] and SUEM840102: Zimm-Bragg parameter sigma $\times 1.0 E 4$ [88]. $\mathbf{c}$ Locations of peptides identified in the secretome and cell peptidomes for the respective precursor proteins with membrane-spanning alpha helices (TMhelix)

MeJA-treated and control peptidome in both the secretome and cell, which is well correlated with the similarity in protein degradation patterns. Since the overall amino acid frequency value does not reflect the order of amino acids in a sequence, we then compared the compositions of five-amino-acid regions in the $\mathrm{N}$ - and C-termini of the identified peptides (Fig. 3a). MeJA treatment did not significantly alter the amino acid patterns in the C- or N-termini. However, the terminal amino acid patterns differed significantly between the secretome and cellular peptidomes (Fig. 3a). These differences might result from the distinct types of proteolytic enzymes located in these compartments. MeJA treatment only slightly altered PDPs while increasing the proteolysis rate and stimulating the degradation of new protein precursors.

\section{Physicochemical properties of the intracellular and extracellular peptidomes differ}

We investigated whether the physicochemical properties of the extracellular and intracellular peptides differ. Using the AAindex database, 544 indexes were calculated for each amino acid in a peptide, and the mean value was calculated [41]. A comparison of intracellular and extracellular peptides revealed significant differences ("Mann-Whitney" test, P-value < e-5) for 197 (36\%) indexes. Moreover, 56 AAindexes differed between the secretome and cellular peptidome with $P$-value $<$ e- 15 ("sigAA" indexes). Among six "sigAA" indexes (Fig. 3b) showing the most pronounced differences between cell and secretome peptides $(P$-value $<\mathrm{e}-25)$, three indexes (KLEP840101, ZIMJ680104 and FAUJ880111) indicated that the secretome peptides tend to have less positively charged amino acids then cell peptides. We then performed Ward's hierarchical clustering of all 544 indexes and identified six clusters. A cluster comprising AAindexes reflecting the hydrophobicity of amino acids was enriched in the secretome (Fisher's exact test, $p$-value $<0.05$ ). For example, secretome peptides had significantly higher partition coefficients [42], hydrophobicity [43], transfer energy and organic solvent/water coefficients [44], as well as lower partition energy [45], which are well-known hydrophobicity indexes [46], compared to cellular peptides.

To gain further insight into differences in precursor proteins for the peptides found in the cells vs. the secretome, we predicted membrane-spanning alpha helices (TMhelix) and their orientations in the precursor proteins for these peptides. Similar portions of protein precursors were 
predicted to contain membrane-spanning alpha helices in the cell and secretome (27\% and 33\%, respectively) (Fig. 3c). However, peptides originating from the regions of proteins predicted to be located inside the cell were significantly overrepresented in the cell peptidome (Fisher's exact test, $P$-value $=1.047 \mathrm{e}-07)$. In contrast, peptides originating from the regions of proteins predicted to be located outside the cell membrane were significantly overrepresented in the secretome (Fisher's exact test, $P$-value $=0.006516$ ). These results provide additional evidence that the identified peptide pool is indeed a part of the secretome rather than an artifact related to sample preparation.

\section{Methyl jasmonate induces antimicrobial activity of the moss secretome}

Peptides play an important role in immune responses in plants. However, little is known about cryptic peptides, which have antimicrobial activity and are generated as a result of the degradation of functionally active proteins. Since the secretome is the first frontier in plant pathogen interactions, we directly tested antimicrobial activity of MeJA-treated secretomes using a serial dilution method with $E$. coli and B. subtilis bacteria (see Methods for details). The one-hour MeJA-treated secretomes restricted the bacterial growth (bacteriostatic effect) in comparison with untreated samples and cultural medium with addition of $0.4 \mathrm{mM} \mathrm{MeJA} \mathrm{(Fig.} 4 \mathrm{a}$ and b), suggesting a possible role of endogenous peptides as a quick-released antimicrobial agent. Some oxylipins have antimicrobial activity, we therefore additionally tested antimicrobial activity of secretomes treated with different concentration of MeJA (0.05 mM, $0.4 \mathrm{mM}$ and 1 $\mathrm{mM}$; Additional file 8: Figure S5). The most pronounced bacteriostatic effect was observed with 0.05 and $0.4 \mathrm{mM}$ MeJA-treated secretome, implying a regulatory role of MeJA rather than functioning as an antimicrobial compound.

We than performed additional experiments to determine, if these results might reflect a release of antimicrobial endogenous peptides during protein degradation. For this, the protease inhibitor cocktail, preventing proteolytic degradation of secreted proteins in tissue culture media, was applied during 1-h MeJA treatment. A significant decrease of the bacteriostatic effect was observed (an unpaired t-test, $P<0.0005$; Additional file 9: Figure S6), suggesting a possible role of endogenous peptides as a quick-released antimicrobial agent.

We then estimated the potential antimicrobial activity of peptides identified in the cell (Additional file 10: Tables S4) and secretome (Additional file 11: Table S5) using three bioinformatic tools: iAMPpred, CAMP and ADAM (see Materials and Methods). We predicted that 3.5\% of all peptides from the secretome might have antimicrobial properties based on data from all three servers. These peptides originated from various groups of protein precursors, including Pp3c2_24160 (glyceraldehyde-3-phosphate dehydrogenase), Pp3c14_17710 (cucumicin) and others. In the culture medium, the most overrepresented peptides were fragments of $\alpha$-expansin protein. Some of these peptides have potential antimicrobial activity, such as the peptides IHNVGGAGDVVSVK and TDINLDLGDGKQG. Treatment with MeJA led to the appearance of potential AMPs originating from some extracellular proteins, such as Pp3c4_16840 (FASCICLIN-LIKE ARABINOGALAC TAN PROTEIN 4) and Pp3c25_3840 (PECTINESTERASE 8-RELATED). We also found that the abundance of the peptide with the highest antimicrobial potential, INIINAPLQGFKIA (pep8, $\mathrm{FC}_{\log 2}=1.3$ ), increased upon MeJA-treatment.

We also analyzed peptide pools identified in the cell peptidome and predicted $4 \%(173)$ as potential antimicrobial peptides. We found an increase in the number of potential antimicrobial peptides (AMPs) in tissues treated with MeJA vs. the control (+10 peptides). We also found that the abundance of $37(21 \%)$ peptides with predicted antimicrobial activity in protonemata was up-regulated $\left(\log _{2} \mathrm{FC}>1\right)$ after MeJA-treatment.

\section{Analysis of the biological activity of synthetic peptides}

To verify the biological activity of the predicted AMPs, we selected eight peptides (five from cell peptidome and three from secretome) based on the following criteria: physicochemical properties, high predicted antimicrobial potential and changes in abundance upon MeJA treatment compared with the control (Table 1). We investigated the antimicrobial activity of the selected peptides in vitro using a serial dilution method with $E$. coli and B. subtilis bacteria. We found that the minimum inhibitory concentration (MIC) for two peptides, LVQIGTKIVGVGRNYAAH (pep1, a fragment of fumarylacetoacetate hydrolase domain-containing protein) from the cell and INIINAPLQGFKIA (pep8, a fragment of the predicted protein) from the cell secretome were 64 and $16 \mu \mathrm{g} / \mathrm{mL}$, respectively (Table 2, Additional file 12: Figure S7). As a positive control, a well-known antimicrobial peptide melittin was used [47]. We obtained a similar MIC for pep8 and melittin (16 and 8 $\mathrm{mkg} / \mathrm{ml}$, respectively), suggesting a possible role identified peptide as an antimicrobial agent. In addition, the cellular peptide KIKVAINGFGRIG (a fragment of the glyceraldehyde-3-phosphate dehydrogenase (GAPDH)), inhibited bacterial growth at a concentration of $128 \mu \mathrm{g} / \mathrm{mL}$ on day 1 after inoculation.

Plant peptides can play a role as damage- or danger-associated molecular patterns (DAMPs) and activate immune responses [48, 49]. We used quantitative RT-PCR analysis (qRT-PCR) to check the ability of 


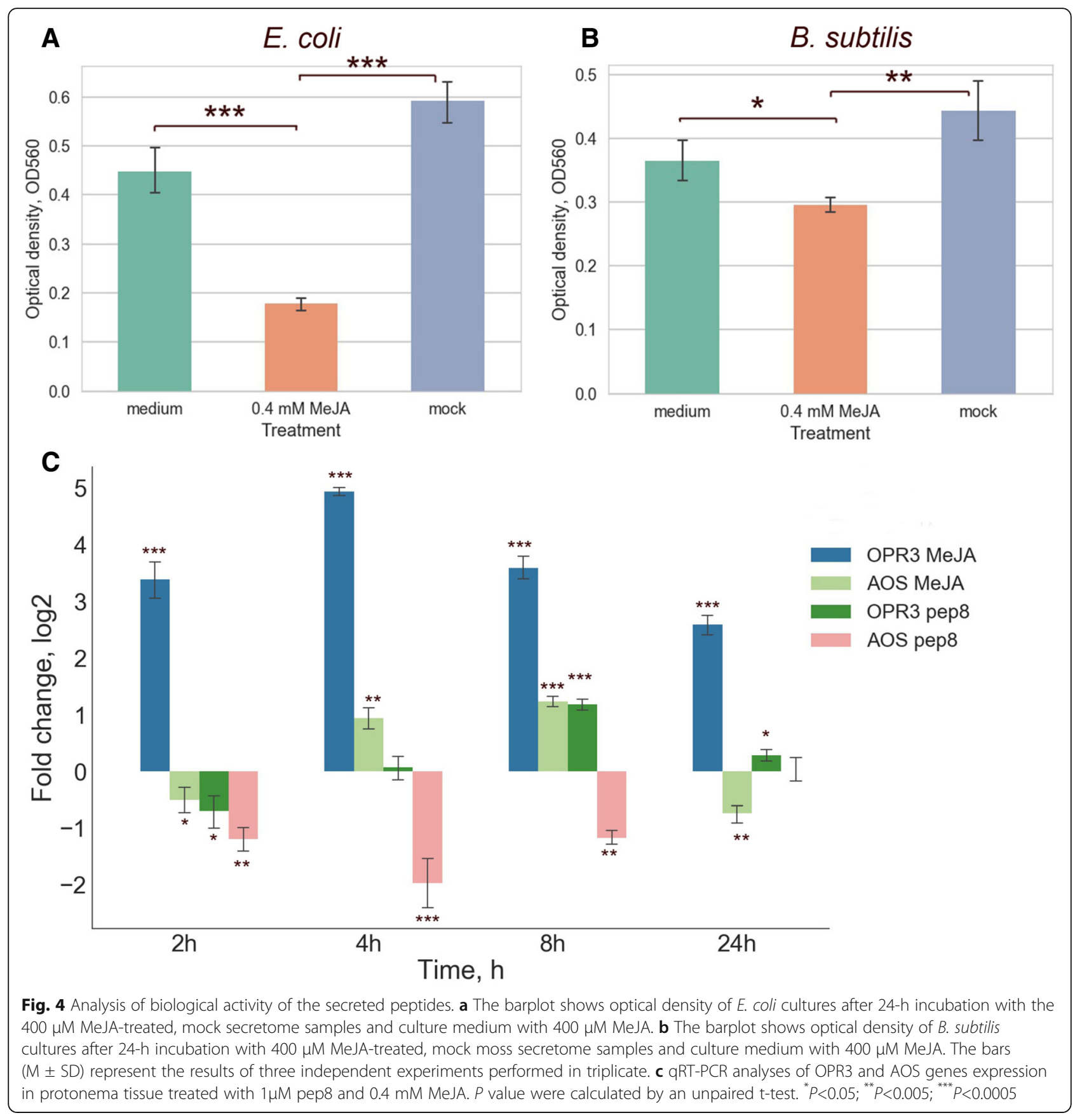

synthetic peptides with antimicrobial activity to induce the transcription of known pathogenesis-related genes, such as allene oxide synthase (AOS), OPDA reductase (OPR3) and phenylalanine ammonia lyase (PAL). According to the previous articles, the transcription of OPR3 is induced by MeJA and pathogens, and expression of PAL is enhanced both by salicylic acid (SA) and MeJA [38-40]. In our study, we observed a clear response of OPR3 to treatment with MeJA, but not SA (Additional file 13: Figure S8). Out of the peptides with antimicrobial activity and all secretome peptides, qRT-PCR showed that the peptide INIINAPLQGFKIA regulates transcription of the OPR3 and AOS genes (Fig. 4c). In parallel, moss protonema was treated with $0.4 \mathrm{mM}$ MeJA as a positive control. We compared the effect of exogenous MeJA on the expression of the OPR3 and AOS genes and found a similar pattern, suggesting additional regulatory role for the peptide (Fig. 4c).

Therefore, our results indicate that some components of the peptide pools have clear antimicrobial and signaling activity. Moreover, treatment with stress hormones can increase the number of potential AMPs and the abundance of such peptides in the cell and secretome. 
Table 1 List of peptides used for synthesis and verification of antimicrobial activity

\begin{tabular}{|c|c|c|c|c|c|}
\hline № & Peptide sequence & Protein & Gene ID & $\begin{array}{l}\text { iAMPpred } \\
\text { index } \\
\text { Antibacterial }\end{array}$ & $\begin{array}{l}\text { Fold change, } \\
\log 2\end{array}$ \\
\hline \multicolumn{6}{|c|}{ Intracellular } \\
\hline 1 & LVQIGTKIVGVGRNYAAH & $\begin{array}{l}\text { Fumarylacetoacetate hydrolase } \\
\text { domain-containing protein } 1\end{array}$ & Pp3c9_26130V3 & 0.832 & 4.2 \\
\hline 2 & AAQGQKIENTKLAGAAGDILSGLAAYGKLD & Predicted & Pp3c22_17930V3 & 0.884 & 0.9 \\
\hline 3 & VAAVAPKFATLKPLG & Chloroplast chaperonin 21 & Pp3c19_4270V3 & 0.811 & 0.7 \\
\hline 4 & KIKVAINGFGRIG & $\begin{array}{l}\text { Glyceraldehyde-3-phosphate } \\
\text { dehydrogenase }\end{array}$ & Pp3c2_24160V3 & 0.998 & -1.9 \\
\hline 5 & IVPTSTGAAKAVALVLPNLK & $\begin{array}{l}\text { Glyceraldehyde-3-phosphate } \\
\text { dehydrogenase }\end{array}$ & Pp3c2_24160V3 & 0.597 & 3.1 \\
\hline \multicolumn{6}{|c|}{ Secretome } \\
\hline 6 & INIINAPLQGFKIA & Predicted & Pp3c14_22870V3 & 0.941 & $\begin{array}{l}1.3 \text { (secretome) } \\
4.1 \text { (cell) }\end{array}$ \\
\hline 7 & TDINLDLGDGKQG & $\begin{array}{l}\text { alpha expansin protein family } \\
\text { EXPA6 }\end{array}$ & Рp3c8_870V3 & 0.513 & 1.6 \\
\hline 8 & WDLLAPYRRGGKIG & Predicted & PhpapaCp032 & 0.507 & -3.2 \\
\hline
\end{tabular}

\section{Discussion}

Protein degradation in plants leads to the generation of thousands of different peptides. While some of these peptides are simply intermediate products in protein degradation, others have distinct biological functions inside or outside the cell $[7,11-14]$. In this study, we analyzed the secretome and cellular peptidomes of the moss $P$. patens under normal conditions and upon treatment with the stress hormone - methyl jasmonate. The global protein degradation patterns of common proteins were significantly different between the cell and the secretome, suggesting a possible difference in the sets of proteolytic activity located in these compartments. Moreover, some of the secreted and intracellular peptides showed clear biological activity. Our data point to the relevance of "active management" of peptide pools in plants, and suggest that the products of protein breakdown are not just passive but contain important biologically active elements. Our research highlights the need for further studies of peptide pools and the biological functions of these peptides in plants.

Stress hormones influence protein degradation pathways Plants contain two major degradation pathways that carry out digestive proteolysis: autophagy and the

Table 2 Minimum inhibitory concentration (MIC) values of peptides

\begin{tabular}{|c|c|c|c|c|}
\hline \multirow[t]{2}{*}{ Peptide sequence } & \multicolumn{2}{|l|}{ E. coli } & \multicolumn{2}{|c|}{ B. subtilis } \\
\hline & $\begin{array}{l}M I C, \\
\mu \mathrm{g} / \mathrm{mL}\end{array}$ & $\%$ inhibition & $\begin{array}{l}\mathrm{MIC} \\
\mu \mathrm{g} / \mathrm{mL}\end{array}$ & $\%$ inhibition \\
\hline LVQIGTKIVGVGRNYAAH & 64 & $>90 \%$ & 64 & $>90 \%$ \\
\hline INIINAPLQGFKIA & 16 & $>90 \%$ & 32 & $>90 \%$ \\
\hline
\end{tabular}

ubiquitin-proteasome system (UPS) [50, 51]. Some studies have shown that oxygenic stress can inhibit $26 \mathrm{~S}$ proteasome activity, thereby increasing the activity of the $20 \mathrm{~S}$ proteasome, which degrades oxygenated proteins [52]. Moreover, UPS is targeted by pathogens to enhance virulence [53]. For example, Pseudomonas syringae pv. tomato (Pst) secretes effector proteins to suppress proteasome activity and block SA signaling [53, 54]. In addition to the UPS, stress conditions or pathogen attack activate various proteases in the apoplast, including phytaspase $[55,56]$. Our results show that stress hormone treatment leads to an increase in the number of unique peptides in the moss protonemata. These peptides are released as a result of degradation of new proteins (phytohormone-induced proteolysis) and changes in the degradation patterns of existing precursors. The latter process leads to the generation of peptide ladders of non-identical but similar peptides between control and MeJA-treated cells.

Thus, stress hormones do not merely induce the degradation of specific repressors of transcription factors, but they also alter the peptide pools in the cell and secretome. Responses to biotic stress appear to include the phytohormone-driven proteolysis of functional proteins, which can lead to the formation of bioactive peptides, e.g., those with antimicrobial activity.

\section{Moss secretome comprises hundreds of different peptides}

Using mass-spectrometry analysis, we identified approximately 500 endogenous peptides generated from functional proteins in liquid culture medium during protonemata growth. We found that MeJA treatment altered the peptide profile of the secretome. The 
corresponding protein precursors are involved in processes including responses to oxidative stress, polyamine metabolism, cell wall biogenesis and so on. MeJA treatment led to the induction and secretion of peptides from various groups of stress proteins. For example, upon MeJA-treatment, fragments from protein precursor PR10 (Pathogenesis Related protein), $70 \mathrm{kDa}$ heat shock protein and MYC transcription factor were detected in the secretome, whereas these three peptides were absent in control samples. Earlier, it has been shown, that PR1 protein from tomato contains cryptic bioactive peptide CAPE1 [14]. This finding supports the notion that MeJA can induce the biosynthesis of biologically active peptides in plant cells, which plays an important role in stress responses.

A previous proteomic analysis of the $P$. patens secretome showed that treatment with chitosan induced the secretion of proteins such as $\alpha$-expansin, pectin methylesterase, photosystem II, lipoxygenase and LEA proteins [37]. We detected peptides from these proteins in both control and MeJA-treated cells. Other study has recently reported the proteome composition of $P$. patens bioreactor supernatants [36]. A complex extracellular proteolytic network including different types of proteases as well as their inhibitors were identified in moss secretome. The contribution of these proteases to the process of extracellular peptidome formation is subject for further evaluation. A slight overlap (Additional file 14: Figure S9) between precursors of the extracellular peptides from our study and secretome proteins from Hoernstein et. al. dataset suggests our conclusions that the extracellular peptidome is not merely a byproduct of extracellular proteins degradation.

Interestingly, we detected only a slight overlap between the secretome and cell peptidome, which raises the question of why such differences occur. First, because protein precursors in the secretome include extracellular and membrane proteins, one of the sources of secretome-specific peptides might be specific extracellular degradation pathways $[57,58]$. Second, some peptides with an intracellular origin could be generated from intracellular proteins inside the cell and then exported into the secretome [57], while their concentration in the cell would be negligible. Third, while some proteases are common to the secretome and cell, the proteins subjected to their action might differ between the cell and secretome.

\section{Mechanisms of peptidome generation might be conservative}

Recent studies on mammals showed that the cell peptidome comprises a large number of intracellular peptides originated from functional proteins and probably produced by the UPS $[59,60]$. In a eukaryotic cell, the majority of 3-25 aa intracellular peptides are formed by the proteasome $[59,61-66]$. Most of the peptides identified in the current study are approximately 15 amino acids in size, indicating that they are possible products of the ubiquitin-proteasome system (UPS) [50, 51]. Interestingly, proteasome inhibitors can alter the pool of endogenous peptides, pointing to a dynamic nature of cell peptidome formation [67].

Some principles of intracellular peptide formation, such as over-representation of $\mathrm{N}$ - and C-terminal fragments, lack of correlation between protein levels and protein degradation fragments suggest a complex picture of cell peptidome formation [68]. For example, about $40 \%$ of intracellular peptides from mouse brain belong to $\mathrm{N}$ - (21\%) or C-terminal (21\%) regions of proteins [60, 68]. According to our results, about $40 \%$ of total peptides in moss cells were raised from C-terminal fragments of proteins while that was not true for secreted peptides. Peptides from mitochondrial proteins constitute approximately $1 / 4$ of the identified intracellular peptides in mouse brain [60, 68]. In our study, most intracellular peptides originated from proteins are involved in photosynthesis, the Calvin cycle, glycolysis and sucrose biosynthesis (Fig. 1b). It seems that organelles, such as mitochondria in mammalian cells and chloroplasts and mitochondria in plants are sources of a large number of intracellular peptides. These findings suggest a great similarity in principles of peptide pools formation in plant and animal cells.

It is interesting to note that intracellular mammalian peptides are extensively secreted, implying their possible functions in cell-cell communication $[60,69]$. We revealed that about $40 \%$ of secreted peptides in moss constitute intracellular peptides or their shorter versions. Despite this, amino acid compositions and physicochemical properties significantly differ between the cell and the secretome peptidomes in moss.

Besides peptides from functional proteins, secretome peptidome in plant and animal encompass a number of post-translationally modified peptide hormones, which regulate different aspects of response to environmental stimuli $[20,69]$. Taken together, these findings suggest that secretome peptidome of animal and plant cell is a complex mixture of specialised peptide hormones and fragments of functional proteins, including full-size or shorter intracellular peptides. Such common features of mammalian and plant peptidomes might indicate a certain conservative mechanism of petidome formation, the whole nature of which is yet to be revealed.

\section{Functional proteins are source of bioactive peptides}

Plant secretome is a source of bioactive peptides, which are induced by stress hormones. In addition to their regulatory functions, secreted peptides can also have 
antibacterial, antifungal and insecticidal functions [22]. A number of studies have shown that functional proteins can be source of antimicrobial peptides [70-72]. Our study shows that MeJA treatment led to an increase in the overall number of endogenous peptides, including peptides with predicted antimicrobial activity. We showed that the peptide KIKVAINGFGRIG, a fragment of glyceraldehyde-3-phosphate dehydrogenase (GAPDH), inhibited bacterial growth. GAPDH-derived antimicrobial peptides have been also found in Saccharomyces cerevisiae and skipjack tuna [73, 74]. These findings suggest a possible role of endogenous peptide pool, released from functional proteins, as a source of bioactive molecules, including antimicrobial ones.

In recent studies, a range of peptides regulating plant immune response has been identified [12, 48]. Interestingly, we found that moss secreted peptides might have antimicrobial and regulatory activities. We identified the peptide INIINAPLQGFKIA, which has the highest predicted antimicrobial potential in the secretome, induced transcription of OPR3 gene $8 \mathrm{~h}$ after treatment and inhibited the transcription of AOS gene in a time-dependent manner. The level of transcription of OPR3 increases under pathogen attack, suggesting a possible role of this peptide in immune response [39]. Previous studies of immune signaling peptides have also shown a timedependent manner of defense gene transcription upon synthetic peptide treatment $[12,14]$. Therefore, our observations lead to the hypothesis that endogenous peptides could represent a rapidly available resource of bioactive peptides with which the plant responds to stress.

\section{Conclusion}

We have presented a comprehensive analysis of the endogenous peptides in both the cells and the secretome of the moss $P$. patens before and after treatment with methyl jasmonate. Peptide pools in the cells and secretome significantly differ in amino acid composition and physicochemical properties. Our data point to a significant alteration of peptide pools in both the secretome and the cells after hormone treatment. This alteration correlates with hormone-specific proteolysis of new functional proteins, along with minor changes in the degradation patterns of existing precursors. We also detected antimicrobial activity in a number of the peptides generated from functionally active proteins upon hormone treatment. Therefore, our data point to the relevance of "active management" of peptide pools in plants, and suggest that the products of protein breakdown are not just passive but contain important biologically active elements. Our research highlights the need for further studies of peptide pools and the biological functions of these peptides in plants.

\section{Methods}

\section{Plant materials and treatments}

Protonemata of the moss $P$. patens subsp. patens ("Gransden 2004", Freiburg) were grown in $200 \mathrm{~mL}$ liquid Knop medium with $500 \mathrm{mg} / \mathrm{L}$ ammonium tartrate under white light with a photon flux of $61 \mu \mathrm{mol} / \mathrm{m}^{2} \cdot \mathrm{s}$ under a 16 -h photoperiod at $24^{\circ} \mathrm{C}$. For mass spectrometry analysis, five-d-old protonema tissue was treated with 0.4 $\mathrm{mM}$ MeJA and incubated for $1 \mathrm{~h}$. To verify the effect of exogenous MeJA on the expression of pathogenesis-related genes, protonema tissue was incubated with $0.05,0.1,0.4$ and $1 \mathrm{mM}$ MeJA or $0.4 \mathrm{mM}$ salicylic acid (SA) for $1 \mathrm{~h}$ under white light. To analyze antimicrobial activity of secretome five-d-old- protonema tissue was treated with different concentration of MeJA. Treatment with cocktail of protease inhibitors was performed according to the dilution 1:200, as recommended by the manufacturer (P1860 Sigma Aldrich, USA). At least three independent biological replicates were used for each type of analysis. To test the gene expression induced by the peptides, five-d-old protonema tissue was treated with either mock solution or $1 \mu \mathrm{M}$ peptide solution and harvested after 2, 4, 8 and 24 h later. The experiments were preformed in four independent biological replicates with three technical replicates.

\section{Peptide extraction}

Intracellular peptides were extracted from moss protonemal tissue as previously described with minor modifications [7]. For peptide extraction from moss tissues, the extraction solution contained $1 \mathrm{M}$ acetic acid in $10 \%$ acetonitrile and $10 \mu \mathrm{L} / \mathrm{mL}$ protease inhibitor cocktail (Sigma-Aldrich, USA). The ground material was placed into cooled extraction solution containing proteinase inhibitor cocktail (Sigma-Aldrich, USA; inhibits serine, cysteine, and aspartic proteases, metalloproteases and aminopeptidases) and homogenized using a Dismembrator S ball mill (Sartorius, Göttingen, Germany) at 2,600 rpm for 2 min with a mixture of glass balls $0.1,0.3$ and $1 \mathrm{~mm}$ in diameter (Sartorius). The suspension was centrifuged at $11,000 \times g$ for $10 \mathrm{~min}$ at $4{ }^{\circ} \mathrm{C}$. The supernatant was transferred to a clean test tube and centrifuged again at $11,000 \times g$ for $10 \mathrm{~min}$ at $4^{\circ} \mathrm{C}$, after which the pellet was discarded. The samples were immediately placed onto a gel filtration column to extract and fractionate the peptides. Gel filtration was carried out on a XK 26/40 GE Healthcare Life Science column filled with sorbent Sephadex G25. Elution was performed with $25 \mathrm{mM}$ Tris- $\mathrm{HCl}, 0.15 \mathrm{mM} \mathrm{NaCl}$ at a flow rate of $1.5 \mathrm{~mL} / \mathrm{min}$. Proteins and peptides were detected on an AKTA pure 25 (GE Healthcare) device at a wavelength of $280 \mathrm{~nm}$. The fraction containing peptides was lyophilized and resuspended in $100 \mu \mathrm{L} \mathrm{5 \%}$ acetonitrile- $0.1 \%$ trifluoroacetic acid, followed by desalting in microcolumns with two $\mathrm{C} 18$ disks (Empore). 
Extracellular peptides were extracted from $400 \mathrm{~mL}$ protonemata culture medium (Knop medium with $500 \mathrm{mg} / \mathrm{L}$ ammonium tartrate). The culture medium was filtered through a $0.22 \mu \mathrm{m}$ membrane filter (Millipore), lyophilized and resuspended in $500 \mu \mathrm{L} 5 \%$ acetonitrile - $0.1 \%$ trifluoroacetic acid, followed by centrifugation at $10,000 \times g$ for $10 \mathrm{~min}$. Peptides were isolated from the culture medium by solid-phase extraction on reverse-phase DSC18 cartridges (Discovery DSC-18, Supelco, USA) using $500 \mu \mathrm{L}$ $50 \%$ and $500 \mu \mathrm{L} 80 \%$ acetonitrile solutions for the elution. The eluted peptides were concentrated in a SpeedVac and resuspended in $15 \mu \mathrm{L} 5 \%$ acetonitrile- $0.1 \%$ trifluoroacetic acid. The pool of peptides was isolated by solid-phase extraction in ZipTip Pipette tips (Millipore) using a $30 \mu \mathrm{L}$ $50 \%$ acetonitrile solution for the elution. Eluted peptides were concentrated in a SpeedVac and resuspended in $15 \mu \mathrm{L}$ $5 \%$ acetonitrile- $0.1 \%$ trifluoroacetic acid, followed by mass-spectrometry analysis of all prepared samples.

\section{Total RNA Isolation and qRT-PCR}

Total RNA from protonemata was isolated as previously described [75]. Quality and quantity were evaluated using electrophoresis on agarose gel with ethidium bromide staining. Total RNA concentration of samples was precisely measured using the Quant-iT ${ }^{\mathrm{Tm}}$ RNA Assay Kit, 5-100 ng on a Qubit 3.0 (Invitrogen, US) fluorometer. cDNA was synthesized using the MMLV RT kit (Evrogen, Russia) according to the manufacturer's recommendations. Random hexamer primers were used to prepare cDNA from $2 \mu \mathrm{g}$ total RNA after DNase treatment. Primers were designed using the PrimerQuest Tool (http://eu.idtdna.com/ Primerquest/Home/Index) (Additional file 15: Table S6). Real-time PCR was performed using the BioMaster HS-qPCR $(2 \times)$ system fluorescent probes (Biolabmix, Russia) on a LightCycler 96 (Roche, Mannheim, Germany). qRT-PCR was carried out in three biological and three technical replicates. cDNA representation was normalized using stably transcribed reference gene actin 5 (Pp1s381_21V6.1). The normalized ratios were obtained using the LightCycler 96 software. Control samples were used as a calibrator.

\section{LC-MS/MS analysis and peptide identification}

Mass-spectrometry analysis was performed in at least three independent biological and three technical repeats. Reverse-phase chromatography was performed with an Ultimate 3000 Nano LC System (Thermo Fisher Scientific), which was coupled to a Q Exactive HF mass spectrometer (Q Exactive ${ }^{\mathrm{TM}}$ HF Hybrid QuadrupoleOrbitrap ${ }^{\mathrm{TM}}$ Mass spectrometer, Thermo Fisher Scientific, USA). Peptide samples were loaded on a Chrom XP C18 trap column $(3 \mu \mathrm{m}, 120 \AA$ A $350 \mathrm{~m} \times 0.5 \mathrm{~mm}$; Eksigent, Dublin, CA) at a flow rate of $3 \mathrm{ml} / \mathrm{min}$ for $10 \mathrm{~min}$ and eluted through a $15-\mathrm{cm}$ long $\mathrm{C} 18$ column with a diameter of $75 \mu \mathrm{m}\left(3 \mu \mathrm{m}\right.$, Acclaim ${ }^{\circ}$ PepMap $^{\text {tm }}$ RSLC, Thermo Fisher Scientific, USA). The injection volume was $5 \mu \mathrm{L}$ and the temperature of the autosampler was kept at $4^{\circ} \mathrm{C}$. The peptides were loaded in mobile phase $\mathrm{A}$ $(0.1 \%(\mathrm{v} / \mathrm{v})$ formic acid) and eluted with a linear $5-35 \%$ gradient of mobile phase B $(80 \%$ acetonitrile, $0.1 \%$ formic acid) at a flow rate of $0.3 \mu \mathrm{L} / \mathrm{min}$. Total run time included initial $10 \mathrm{~min}$ of column equilibration to mobile phase $\mathrm{A}$, then a linear $5-35 \%$ gradient of mobile phase B over $65 \mathrm{~min}, 5 \mathrm{~min}$ to reach $99 \%$ mobile phase B, flushing 5 min with $99 \%$ mobile phase B and 5 min re-equilibration with mobile phase A. Column temperature was kept at $40^{\circ} \mathrm{C}$. Mass spectra were acquired at a resolution of 60,000 (MS) and 15,000 (MS/MS) in a range of $400-1,500 \mathrm{~m} / \mathrm{z}$ (MS) and $200-2,000 \mathrm{~m} / \mathrm{z}$ (MS/MS). An isolation threshold of 67,000 was determined for precursor selection and (up to) the top-10 precursors were subjected to fragmentation with high-energy collisional dissociation (HCD) at $25 \mathrm{NCE}$ and $100 \mathrm{~ms}$ activation time. Other settings: charge exclusion unassigned, 1, >6; peptide match - preferred; exclude isotopes - on; dynamic exclusion - $20 \mathrm{~s}$ was enabled.

Mass-spectrometry data were searched with MaxQuant v1.5.8.3 against a database containing the protein sequences from Phytozome v12.0 merged with chloroplast and mitochondrial proteins (33053 entries) and sequences from a database of common contaminant proteins [76]. The MaxQuant protein FDR filter was disabled, while the peptide FDR remained at $1 \%$. The parameter "Digestion Mode" was set to "unspecific", and modifications were not allowed. All other parameters were left at default values. Features of PSMs (length, intensity, number of spectra, Andromeda score, intensity coverage and peak coverage) were extracted from MaxQuant's msms.txt files. Statistical analysis including the quantification of peptides based on extracted ion chromatograms (XICs) values was performed in Perseus (v1.6.0.7) [77].

\section{Retention Time (RT) peptides identification by MRM-MS}

For MRM, 6 pmol of retention time (iRT) peptides mix (Biognosys, Switzerland) was added to $200 \mathrm{~mL}$ of a liquid medium or to $5 \mathrm{~mL}$ of extraction solution before intracellular peptides isolation. MRM-MS analysis was performed on on QTRAP 4500 (Sciex, USA) triple quadrupole mass spectrometer equipped with a NanoSpray III ion source (Sciex, USA) coupled to a nanoLC Ultra 2D+ nano-HPLC system (Eksigent, USA). The HPLC system was configured in a trap-elute mode. A mixture of $98.9 \%$ water, $1 \%$ methanol, and $0.1 \%$ formic acid (v/v) was used as the sample loading solution and mobile phase A. Mobile phase B was $99.9 \%$ ACN, $0.1 \%$ formic acid $(\mathrm{v} / \mathrm{v})$. Samples were loaded on a trap column (10 mm, 100 um i.d., Aeris Peptide XB-C18, 2.6 uM, 
$100 \mathrm{~A})$ at a flow rate of $2.5 \mu \mathrm{L} / \mathrm{min}$ over $10 \mathrm{~min}$ and eluted through the separation column $(20 \mathrm{~cm}, 75 \mathrm{um}$ i.d., Aeris Peptide XB-C18, $2.6 \mathrm{uM}, 100 \mathrm{~A}$ ) at a flow rate of $300 \mathrm{~nL} / \mathrm{min}$. Total run time including initial 10 min of column equilibration to mobile phase A (0.1\% formic acid), then gradient from $10-40 \%$ mobile phase B over 30 min, 2 min to reach 95\% mobile phase B, flushing $10 \mathrm{~min}$ with $95 \%$ mobile $\mathrm{B}$ and $5 \mathrm{~min}$ re-equilibration to mobile phase A $15 \mathrm{~min}$. The chromatographic columns were thermostated at $50^{\circ} \mathrm{C}$.

Target peptides were measured in duplicate, which were averaged and total fragment peak area and normalized to each peptides' mean signal was used as a proxy of peptide abundances. Transition list was created after evaluation of all theoretical $\mathrm{b}$ and $\mathrm{y}$ fragments of charge +1 of precursor ions of charges +2 and +3 . Top 5 transitions of most intense precursor ions were used for further measurements after analysis of synthetic peptide samples. MRM data was acquired in positive ion mode in non-scheduled MRM method with $1.49 \mathrm{~s}$ total scan time and dwell time $10 \mathrm{msec}(\mathrm{Q} 1$ and Q3 resolution set to "UNIT" - 0.7 Da FWHH), pause between mass ranges was $5 \mathrm{~ms}$ ). Processing of the data included peak selection (with manual review for interference and missing signals), peak integration and export utilizing Skyline software. Further analysis was performed by a homemade script in $\mathrm{R}$.

\section{Prediction of antimicrobial activity}

The antimicrobial potential of peptides was predicted based on sequence using three servers: CAMP (http:// www.camp3.bicnirrh.res.in), iAMPpred (http://cabgrid.res.in:8080/amppred/) and ADAM (http://bioinformatics.cs.ntou.edu.tw/ADAM/links.html), which use machine-learning algorithms (support vector machines [SVM]) to predict the antimicrobial activity in a peptide. For CAMP and $i$ AMPpred, a threshold value of 0.5 was used to predict antimicrobial activity. For ADAM, a threshold value of 0 was used to predict antimicrobial activity. Only antimicrobial peptides with a probability of misclassification less than $5 \%$ were used.

\section{GO enrichment analysis}

The topGO bioconductor $\mathrm{R}$ package was used to estimate GO enrichment (Alexa and Rahnenfuhrer, 2010) using the Fisher's exact test in conjunction with the "classic" algorithm (false discovery rate $[\mathrm{FDR}]<0.05$ ). Gene Ontology (GO) terms assigned to $P$. patens genes were downloaded from Phytozome. Only GO terms containing $>5$ genes in a background dataset were considered in the enrichment analysis. Redundant GO terms were removed using the web-based tool REVIGO (Supek et al., 2011).

\section{Statistical analysis and visualization}

All statistical calculations were performed using $\mathrm{R}$ programming language. For continuous variables without normal distribution, the nonparametric "Mann-Whitney-Wilcoxon U-Test" test was used while Student's t-Test was applied to normally distributed data. To visualize the results histograms and box plots were built by ggplot2 library in $\mathrm{R}$ [78], the Venn diagrams were drawn using the VennDiagram library in $R$ [79]. PDP heatmaps were drawn by ComplexHeatmap library in $\mathrm{R}$, using the matrix prepared by a custom python script Degradome.py. Matrix for PDP analysis were constructed by splitting a protein sequence into 10 equal windows followed by counting the number of overlaps between the window coordinates and start coordinates of MS peptides corresponding to the protein. To estimate amino acid biases custom python script (AAbiases.py) was applied. The calculation of physico-chemical properties of peptides was accompanied by AAIndex.py script (http://pydoc.net/ pydpi/1.0/pydpi.protein.AAIndex/). Logos pictures were generated by WebLogo service [80]. All python scripts used in this work are available at GitHub repository (https://github.com/Kirovez/Secretome).

\section{Peptide synthesis}

The peptides were synthesized by Shanghai Ruifu Chemical Co., Ltd. (Shanghai, China). The purity of the peptides was $>95 \%$, and their molecular weights were confirmed by mass-spectrometry analysis. The peptides were resuspended in sterile water to a concentration of $2,560 \mu \mathrm{g} / \mathrm{mL}$ and stored at $-80^{\circ} \mathrm{C}$.

\section{Antimicrobial activity assays}

Antimicrobial activity was determined in 96-well polypropylene microtiter plates (Corning, cat. no. CLS3879, Corning, USA) using the standard microtiter dilution method in accordance with general practice [81]. The two bacterial strains - Escherichia coli (K-12 substr. MG1655) and Bacillus subtilis (168HT) - were stored with $10 \%$ glycerol at $-70{ }^{\circ} \mathrm{C}$ until use. Bacterial cultures were grown in $\mathrm{LB}$ medium for $16 \mathrm{~h}$ at $37^{\circ} \mathrm{C}$, and $100-\mu \mathrm{L}$ aliquots of culture were used to inoculate $9.9 \mathrm{~mL}$ Mueller-Hinton Broth (MHB, Difco; Becton Dickinson Diagnostics) medium (Beef extract $2 \mathrm{~g} / \mathrm{L}$, Acid digest of Casein $17.5 \mathrm{~g} / \mathrm{L}$, Starch $1.5 \mathrm{~g} / \mathrm{L}$ ). The cultures were incubated on a shaker to a final concentration of $1 \times 10^{8}$ $\mathrm{CFU} / \mathrm{mL}$, followed by serial dilution in $2 \times$ MHB growth medium to prepare test cultures at a concentration of $1 \times 10^{6} \mathrm{CFU} / \mathrm{mL}$. $50 \mathrm{ml}$ of a lyophilized secretome sample was dialyzed against normal saline $(0.9 \%)$ for $16 \mathrm{~h}$ at $25^{\circ} \mathrm{C}$ using CelluSep $\mathrm{H} 1$ membranes (MFPI, USA). Microtiter plate wells each received aliquots of $50 \mu \mathrm{L}$ of the culture suspension, followed by the addition of 50 $\mu \mathrm{L}$ of the diluted secretome sample. As a control, both 
pure liquid medium and medium with addition of 400 $\mu \mathrm{M}$ MeJA were used. After incubation at $37^{\circ} \mathrm{C}$ for $24 \mathrm{~h}$, the antimicrobial susceptibility was monitored by measuring the optical absorbance at $570 \mathrm{~nm}$ using a microplate reader. 1/32 diluted samples were used for visualization of results.

A serial dilution method in sterile 96 Well Collection Plates (Corning 3870) in liquid MHB medium was used to define the minimum inhibitory concentration (MIC) of the peptides against E. coli K-12 MG 1655 and B. subtilis $168 \mathrm{HT}$ as previously described [81]. Diluted peptide $(50 \mu \mathrm{L})$ in $\mathrm{MHB}$ medium was added to each well at the appropriate concentration (128 to $0.25 \mu \mathrm{g} / \mathrm{mL}$ ), along with $50 \mu \mathrm{L}$ of bacterial suspension at a concentration of $10^{6} \mathrm{CFU} / \mathrm{mL}$ of microbial cells. The experiment was carried out in three replicates. Liquid MHB medium without the addition of the peptide used as a negative control. The plates were incubated at $37^{\circ} \mathrm{C}$ for $20 \mathrm{~h}$ without mixing. The MIC of the peptides was assessed visually and by measuring the spectrophotometric absorbance at $570 \mathrm{~nm}$ to identify the concentration that inhibited the visible growth of bacteria.

\section{Additional files}

\section{Additional file 1: Figure S1. A workflow of the peptidomic analysis.} (PDF $257 \mathrm{~kb}$ )

Additional file 2: Figure S2. The MRM chromatogram of eleven standard RT peptides added in cell and secretome samples. (PDF $613 \mathrm{~kb}$ ) Additional file 3: Table S1. The list of synthetic RT peptides identified by MRM-MS in cell and secretome samples. (XLSX $11 \mathrm{~kb}$ )

Additional file 4: Table S2. List of intracellular endogenous peptides identified in control and MeJA-treated protonemata. (XLSX $540 \mathrm{~kb}$ )

Additional file 5: Figure S3. The distribution of the log2-transormed (log2_FC) peptide intensities based on Xtracted lon Chromatogram (XIC) values. (PDF $129 \mathrm{~kb}$ )

Additional file 6: Figure S4. TreeMap showing GO enrichment analysis results for all protein precursors for cell peptides. (PDF $184 \mathrm{~kb}$ )

Additional file 7: Table S3. List of secreted peptides identified in control and MeJA-treated protenamata. (XLSX $67 \mathrm{~kb}$ )

Additional file 8: Figure S5. The barplot shows optical density of E. coli and B. subtilis cultures after 24-h incubation with secretome samples treated with different concentration of MeJA. The bars $(M \pm S D)$ represent the results of three independent experiments performed in triplicate. (PDF $220 \mathrm{~kb}$ )

Additional file 9: Figure S6. The barplot shows optical density of E. coli and B. subtilis cultures after 24-h incubation with secretome samples. Secretome+inhibitor+MeJA - secretomes of moss protonema treated with $400 \mu \mathrm{M}$ MeJA and the protease inhibitor cocktail; secretome +MeJA - secretomes of moss protonemata treated with the $400 \mu \mathrm{M}$ MeJA; secretome+inhibitor - secretomes of moss protonema treated with the protease inhibitor cocktail. The bars $(M \pm S D)$ represent the results of three independent experiments performed in triplicate. (PDF $202 \mathrm{~kb}$ )

Additional file 10: Table S4. Antimicrobial potential of intracellular peptides predicted using three tools: CAMP, iAMPpred and ADAM. (XLSX $255 \mathrm{~kb}$ )

Additional file 11: Table S5. Antimicrobial potential of secreted peptides predicted using three tools: CAMP, iAMPpred and ADAM (XLSX $35 \mathrm{~kb})$
Additional file 12: Figure S7. Analysis of minimal inhibitory concentration (MIC) for the two peptides (Pep1- LVQIGTKIVGVGRNYAAH and Pep8- INIINAPLQGFKIA). Melittin was used as a positive control. The barplot shows optical density of B. subtilis and E. coli cultures after 24-h incubation with different peptide concentrations. (PDF $171 \mathrm{~kb}$ )

Additional file 13: Figure S8. (A) Results of quantitative polymerase chain reaction (qRT-PCR) for PAL and OPR genes after treatment of protonemata with $50 \mu \mathrm{M}, 100 \mu \mathrm{M}, 400 \mu \mathrm{M}$ and $1 \mathrm{mM}$ methyl jasmonate (MeJA). (B) Results of qRT-PCR for PAL and OPR genes after treatment of protonemata with $10 \mu \mathrm{M}, 100 \mu \mathrm{M}, 400 \mu \mathrm{M}$ and $1 \mathrm{mM}$ salicylic acid (SA); The normalized ratios and standard deviation of three independent triplicate experiments are shown. (PDF $182 \mathrm{~kb}$ )

Additional file 14: Figure S9. Venn diagram showing a comparison between protein precursors of our control dataset and proteome of $\mathrm{P}$. patens bioreactor supernatants (Hoerstein et. al. 2018). (PDF $250 \mathrm{~kb}$ )

Additional file 15: Table S6. List of primers used for qRT-PCR analysis. (XLSX $8 \mathrm{~kb})$

\section{Abbreviations}

AMP: Antimicrobial peptides; CLE: CLAVATA3 CLV3/ENDOSPERM SURROUNDING REGION ESR; CRP: Cysteine-Rich Peptides; EXPA6: Alpha-expansin; GAPDH: Glyceraldehyde-3-phosphate dehydrogenase; MeJA: Methyl jasmonic acid; MIC: Minimum inhibitory concentration; PDPs: Protein degradation patterns; PR10: Pathogenesis Related protein; PSK: Phytosulfokine; SA: Salicylic acid; UPS: Ubiquitin-proteasome system; XIC: Extracted ion chromatogram

\section{Acknowledgments}

Some of mass spectrometric measurements were performed using the equipment of the "Human Proteome" Core Facility of the Orekhovich Institute of Biomedical Chemistry (Russia) which is supported by the Ministry of Education and Science of the Russian Federation.

\section{Funding}

This work was supported by the Russian Science Foundation (project No. 17-14-01189). The founding sponsor had no role in the design of the study; in the collection, analyses, or interpretation of data; in the writing of the manuscript, and in the decision to publish the results.

\section{Availability of data and materials}

All data generated or analyzed during this study are included in the manuscript. The mass spectrometry data have been deposited to the ProteomeXchange Consortium via the PRIDE [82] partner repository with the dataset identifiers PXD009530 and PXD009532.

\section{Authors' contributions}

IF, RA, IK wrote the manuscript. RA, IL conducted peptide extraction and contributed to the analysis of the data. AK, AF, AM participated in the gene expression analysis. EG, VL, SE conducted microbiological experiments. VZ, IB, $\mathrm{OB}, \mathrm{DN}$ conducted mass-spectrometry analysis. VI, VG designed and supervised the study. All authors read and approved the final manuscript.

\section{Ethics approval and consent to participate}

This work was performed with descendant of the Gransden 2004 strain. The Gransden 2004 strain (accession number 40001) is available through the International Moss Stock Center IMSC (http://www.moss-stock-center.org/). The experimental research on plants performed in this study complies with institutional, national and international guidelines.

\section{Consent for publication}

Not applicable.

Competing interests

The authors declare that they have no competing interests.

\section{Publisher's Note}

Springer Nature remains neutral with regard to jurisdictional claims in published maps and institutional affiliations. 


\section{Author details}

'Laboratory of Proteomics, Shemyakin and Ovchinnikov Institute of Bioorganic Chemistry, Russian Academy of Sciences, Moscow, Russia. ${ }^{2}$ Federal Research and Clinical Center of Physical-Chemical Medicine of Federal Medical Biological Agency, Moscow, Russia. ${ }^{3}$ Moscow Institute of Physics and Technology, Dolgoprudny, Moscow region, Russia. ${ }^{4}$ Institute of Biomedical Chemistry, Moscow, Russia. ${ }^{5}$ Department of Analytical Chemistry, Faculty of Chemistry, Lomonosov Moscow State University, Moscow, Russia. ${ }^{6}$ Biological Faculty, Lomonosov Moscow State University, Moscow, Russia.

\section{Received: 25 July 2018 Accepted: 20 December 2018}

\section{Published online: 07 January 2019}

\section{References}

1. Tavormina P, De Coninck B, Nikonorova N, De Smet I, Cammue BPA. The Plant Peptidome: An Expanding Repertoire of Structural Features and Biological Functions. Plant Cell. 2015;27(8):2095-118.

2. Albert M. Peptides as triggers of plant defence. J Exp Bot. 2013;64(17):5269-79.

3. Czyzewicz N, Yue K, Beeckman T, De Smet I. Message in a bottle: small signalling peptide outputs during growth and development. J Exp Bot. 2013;64(17):5281-96

4. Matsubayashi Y. Posttranslationally Modified Small-Peptide Signals in Plants. Annu Rev Plant Biol. 2014;65:385-413.

5. Hanada K, Higuchi-Takeuchi M, Okamoto M, Yoshizumi T, Shimizu M, Nakaminami K, Nishi R, Ohashi C, lida K, Tanaka M, et al. Small open reading frames associated with morphogenesis are hidden in plant genomes. Proc Natl Acad Sci U S A. 2013;110(6):2395-400.

6. Matsumoto A, Pasut A, Matsumoto M, Yamashita R, Fung J, Monteleone E, Saghatelian A, Nakayama Kl, Clohessy JG, Pandolfi PP. mTORC1 and muscle regeneration are regulated by the LINC00961-encoded SPAR polypeptide. Nature. 2017;541(7636):228-32.

7. Fesenko IA, Arapidi GP, Skripnikov AY, Alexeev DG, Kostryukova ES, Manolov Al, Altukhov IA, Khazigaleeva RA, Seredina AV, Kovalchuk SI, et al. Specific pools of endogenous peptides are present in gametophore, protonema and protoplast cells of the moss Physcomitrella patens. BMC Plant Biol. 2015;15:87.

8. Hattori T, Yamada T, Morikawa H, Marutani T, Tsutsumi K, Nishino K, Shimizu T, Nishi Y, Kiso Y, Mukai H. Generation of monoclonal antibodies against mitocryptide-2: toward a new strategy to investigate the biological roles of cryptides. J Pept Sci. 2017;23(7-8):610-7.

9. Samir P, Link AJ. Analyzing the Cryptome: Uncovering Secret Sequences. Aaps J. 2011;13(2):152-8

10. Pimenta DC, Lebrun I. Cryptides: Buried secrets in proteins. Peptides. 2007; 28(12):2403-10

11. Schmelz EA, Carroll MJ, LeClere S, Phipps SM, Meredith J, Chourey PS, Alborn HT, Teal PEA. Fragments of ATP synthase mediate plant perception of insect attack. Proc Natl Acad Sci U S A. 2006;103(23):8894-9.

12. Pearce G, Yamaguchi Y, Barona G, Ryan CA. A subtilisin-like protein from soybean contains an embedded, cryptic signal that activates defenserelated genes. Proc Natl Acad Sci U S A. 2010;107(33):14921-5.

13. Yamaguchi Y, Barona G, Ryan CA, Pearce G. GmPep914, an Eight-Amino Acid Peptide Isolated from Soybean Leaves, Activates Defense-Related Genes. Plant Physiol. 2011;156(2):932-42.

14. Chen $Y L$, Lee $C Y$, Cheng KT, Chang WH, Huang RN, Nam HG, Chen YR. Quantitative Peptidomics Study Reveals That a Wound-Induced Peptide from PR-1 Regulates Immune Signaling in Tomato. Plant Cell. 2014;26(10): 4135-48.

15. Breen S, Solomon PS, Bedon F, Vincent D. Surveying the potential of secreted antimicrobial peptides to enhance plant disease resistance. Front Plant Sci. 2015;6:900

16. Robert S, Goulet MC, D'Aoust MA, Sainsbury F, Michaud D. Leaf proteome rebalancing in Nicotiana benthamiana for upstream enrichment of a transiently expressed recombinant protein. Plant Biotechnol J. 2015;13(8):1169-79.

17. Croager E. Plant cell biology - Protein degradation protects plants. Nat Rev Mol Cell Bio. 2004;5(2):85.

18. Toshima E, Nanjo Y, Komatsu S, Abe T, Matsuura H, Takahashi K. Proteomic analysis of Physcomitrella patens treated with 12-oxo-phytodienoic acid, an important oxylipin in plants. Biosci Biotech Bioch. 2014;78(6):946-53.

19. Zhang Y, Pennerman KK, Yang F, Yin G. Maize MeJA-responsive proteins identified by high-resolution 2-DE PAGE. Data Brief. 2015;5:129-33.
20. Patel N, Mohd-Radzman NA, Corcilius L, Crossett B, Connolly A, Cordwell SJ, Ivanovici A, Taylor K, Williams J, Binos S, et al. Diverse Peptide Hormones Affecting Root Growth Identified in the Medicago truncatula Secreted Peptidome. Mol Cell Proteomics. 2018;17(1):160-74.

21. Michel M, Baczek T, Studzinska S, Bodzioch K, Jonsson T, Kaliszan R, Buszewski B. Comparative evaluation of high-performance liquid chromatography stationary phases used for the separation of peptides in terms of quantitative structure-retention relationships. J Chromatogr A. 2007:1175(1):49-54.

22. Cools TL, Struyfs C, Cammue BPA, Thevissen K. Antifungal plant defensins: increased insight in their mode of action as a basis for their use to combat fungal infections. Future Microbiol. 2017;12(5):441-54.

23. Thomma BPHJ, Cammue BPA, Thevissen K. Plant defensins. Planta. 2002; 216(2):193-202.

24. Thevissen K, de Mello Tavares P, Xu D, Blankenship J, Vandenbosch D, Idkowiak-Baldys J, Govaert G, Bink A, Rozental S, de Groot PW, et al. The plant defensin RsAFP2 induces cell wall stress, septin mislocalization and accumulation of ceramides in Candida albicans. Mol Microbiol. 2012:84(1):166-80.

25. Spelbrink RG, Dilmac N, Allen A, Smith TJ, Shah DM, Hockerman GH. Differential antifungal and calcium channel-blocking activity among structurally related plant defensins. Plant physiol. 2004;135(4):2055-67.

26. Mello EO, Ribeiro SF, Carvalho AO, Santos IS, Da Cunha M, Santa-Catarina C, Gomes VM. Antifungal activity of PVD1 defensin involves plasma membrane permeabilization, inhibition of medium acidification, and induction of ROS in fungi cells. Curr Microbiol. 2011;62(4):1209-17.

27. Krause C, Richter S, Knoll C, Jurgens G. Plant secretome - From cellular process to biological activity. Bba-Proteins Proteom. 2013;1834(11):2429-41.

28. Silverstein KAT, Moskal WA, Wu HC, Underwood BA, Graham MA, Town CD, VandenBosch KA. Small cysteine-rich peptides resembling antimicrobial peptides have been under-predicted in plants. Plant J. 2007:51(2):262-80.

29. Djordjevic MA, Oakes M, Wong CE, Singh M, Bhalla P, Kusumawati L, Imin N. Border sequences of Medicago truncatula CLE36 are specifically cleaved by endoproteases common to the extracellular fluids of Medicago and soybean. J Exp Bot. 2011:62(13):4649-59.

30. Betsuyaku S, Takahashi F, Kinoshita A, Miwa H, Shinozaki K, Fukuda H, Sawa S. Mitogen-Activated Protein Kinase Regulated by the CLAVATA Receptors Contributes to Shoot Apical Meristem Homeostasis. Plant Cell Physiol. 2011; 52(1):14-29.

31. Wang GD, Fiers M. CLE peptide signaling during plant development. Protoplasma. 2010:240(1-4):33-43.

32. Muller R, Bleckmann A, Simon R. The receptor kinase CORYNE of Arabidopsis transmits the stem cell-limiting signal CLAVATA3 independently of CLAVATA1. Plant cell. 2008;20(4):934-46.

33. Tang WH, Ezcurra I, Muschietti J, McCormick S. A cysteine-rich extracellular protein, LAT52, interacts with the extracellular domain of the pollen receptor kinase LePRK2. Plant cell. 2002;14(9):2277-87.

34. Butenko MA, Patterson SE, Grini PE, Stenvik GE, Amundsen SS, Mandal A, Aalen RB. INFLORESCENCE DEFICIENT IN ABSCISSION controls floral organ abscission in arabidopsis and identifies a novel family of putative ligands in plants. Plant cell. 2003;15(10):2296-307.

35. Ni J, Guo YF, Jin HY, Hartsell J, Clark SE. Characterization of a CLE processing activity. Plant Mol Biol. 2011;75(1-2):67-75.

36. Hoernstein SNW, Fode B, Wiedemann G, Lang D, Niederkruger $H$, Berg B, Schaaf A, Frischmuth T, Schlosser A, Decker EL, et al. Host Cell Proteome of Physcomitrella patens Harbors Proteases and Protease Inhibitors under Bioproduction Conditions. J Proteome Res. 2018:17(11):3749-60.

37. Lehtonen MT, Takikawa Y, Ronnholm G, Akita M, Kalkkinen N, Aholalivarinen $\mathrm{E}$, Somervuo P, Varjosalo M, Valkonen JP. Protein secretome of moss plants (Physcomitrella patens) with emphasis on changes induced by a fungal elicitor. J Proteome Res. 2014;13(2):447-59.

38. Liu H, Carvalhais LC, Kazan K, Schenk PM. Development of marker genes for jasmonic acid signaling in shoots and roots of wheat. Plant Signal Behav. 2016;11(5):e1176654

39. Ponce De Leon I, Schmelz EA, Gaggero C, Castro A, Alvarez A, Montesano M. Physcomitrella patens activates reinforcement of the cell wall, programmed cell death and accumulation of evolutionary conserved defence signals, such as salicylic acid and 12-oxophytodienoic acid, but not jasmonic acid, upon Botrytis cinerea infection. Mol Plant Pathol. 2012;13(8):960-74. 
40. Belhadj A, Telef N, Saigne C, Cluzet S, Barrieu F, Hamdi S, Merillon JM. Effect of methyl jasmonate in combination with carbohydrates on gene expression of PR proteins, stilbene and anthocyanin accumulation in grapevine cell cultures. Plant Physiol Biochem. 2008;46(4):493-9.

41. Kawashima S, Pokarowski P, Pokarowska M, Kolinski A, Katayama T, Kanehisa M. AAindex: amino acid index database, progress report 2008. Nucleic Acids Res. 2008;36(Database issue):D202-5.

42. Garel JP, Filliol D, Mandel P. Partition coefficients of amino acids, nucleobases, nucleosides and nucleotides in a saline solvent system. J Chromatogr. 1973;78(2):381-91.

43. Wilce MCJ, Aguilar MI, Hearn MTW. Physicochemical Basis of Amino-Acid Hydrophobicity Scales - Evaluation of 4 New Scales of Amino-Acid Hydrophobicity Coefficients Derived from Rp-Hplc of Peptides. Anal Chem. 1995;67(7):1210-9.

44. Nozaki Y, Tanford C. The solubility of amino acids and two glycine peptides in aqueous ethanol and dioxane solutions. Establishment of a hydrophobicity scale. J Biol Chem. 1971;246(7):2211-7.

45. Guy HR. Amino-Acid Side-Chain Partition Energies and Distribution of Residues in Soluble-Proteins. Biophys J. 1985;47(1):61-70.

46. Simm S, Einloft J, Mirus O, Schleiff E. 50 years of amino acid hydrophobicity scales: revisiting the capacity for peptide classification. Biol Res. 2016:49(1):31.

47. Raghuraman H, Chattopadhyay A. Melittin: a membrane-active peptide with diverse functions. Biosci Rep. 2007;27(4-5):189-223.

48. Ziemann S, van der Linde K, Lahrmann U, Acar B, Kaschani F, Colby T, Kaiser M, Ding Y, Schmelz E, Huffaker A, et al. An apoplastic peptide activates salicylic acid signalling in maize. Nat Plants. 2018;4(3):172-80.

49. Zheng $X$, Kang S, Jing Y, Ren Z, Li L, Zhou JM, Berkowitz G, Shi J, Fu A, Lan W, et al. Danger-Associated Peptides Close Stomata by OST1-Independent Activation of Anion Channels in Guard Cells. Plant cell. 2018;30(5):1132-46.

50. Minina EA, Moschou PN, Bozhkov PV. Limited and digestive proteolysis: crosstalk between evolutionary conserved pathways. New Phytol. 2017; 215(3):958-64

51. Araujo WL, Tohge T, Ishizaki K, Leaver CJ, Fernie AR. Protein degradation an alternative respiratory substrate for stressed plants. Trends Plant Sci. 2011;16(9):489-98.

52. Kurepa J, Wang S, Li Y, Smalle J. Proteasome regulation, plant growth and stress tolerance. Plant Signal Behav. 2009;4(10):924-7.

53. Ustun S, Hafren A, Liu Q, Marshall RS, Minina EA, Bozhkov PV, Vierstra RD, Hofius D. Bacteria Exploit Autophagy for Proteasome Degradation and Enhanced Virulence in Plants. Plant Cell. 2018;30(3):668-85.

54. Cirera-Domenech E, Estrada-Tejedor R, Broto-Puig F, Teixido J, Gassiot-Matas M, Comellas L, Lliberia JL, Mendez A, Paz-Estivill S, Delgado-Ortiz MR. Quantitative structure-retention relationships applied to liquid chromatography gradient elution method for the determination of carbonyl-2,4-dinitrophenylhydrazone compounds. Journal of chromatography A. 2013;1276:65-77.

55. Chichkova NV, Shaw J, Galiullina RA, Drury GE, Tuzhikov Al, Kim SH, Kalkum M, Hong TB, Gorshkova EN, Torrance L, et al. Phytaspase, a relocalisable cell death promoting plant protease with caspase specificity. EMBO J. 2010; 29(6):1149-61.

56. Vartapetian AB, Tuzhikov Al, Chichkova NV, Taliansky M, Wolpert TJ. A plant alternative to animal caspases: subtilisin-like proteases. Cell Death Differ. 2011;18(8):1289-97.

57. Guillot A, Boulay M, Chambellon E, Gitton C, Monnet V, Juillard V. Mass Spectrometry Analysis of the Extracellular Peptidome of Lactococcus lactis: Lines of Evidence for the Coexistence of Extracellular Protein Hydrolysis and Intracellular Peptide Excretion. J Proteome Res. 2016; 15(9):3214-24

58. Lichtenthaler SF, Lemberg MK, Fluhrer R. Proteolytic ectodomain shedding of membrane proteins in mammals - hardware, concepts, and recent developments. The EMBO Journal. 2018;37(15):e99456.

59. Ferro E, Rioli V, Castro L, Fricker L. Intracellular peptides: From discovery to function. Proteomics Clin Appl. 2014;3:143-51.

60. Gelman JS, Dasgupta S, Berezniuk I, Fricker LD. Analysis of peptides secreted from cultured mouse brain tissue. Biochim Biophys Acta. 2013; 1834(11):2408-17.

61. Dasgupta S, Castro LM, Dulman R, Yang C, Schmidt M, Ferro ES, Fricker LD Proteasome inhibitors alter levels of intracellular peptides in HEK293T and SH-SY5Y cells. PloS one. 2014;9(7):e103604.

62. Goldberg AL. Protein degradation and protection against misfolded or damaged proteins. Nature. 2003;426(6968):895-9.
63. Saric T, Graef Cl, Goldberg AL. Pathway for degradation of peptides generated by proteasomes - A key role for thimet oligopeptidase and other metallopeptidases. J Biol Chem. 2004;279(45):46723-32.

64. Tagore DM, Nolte WM, Neveu JM, Rangel R, Guzman-Rojas L, Pasqualini R, Arap W, Lane WS, Saghatelian A. Peptidase substrates via global peptide profiling. Nat Chem Biol. 2009;5(1):23-5.

65. Nussbaum AK, Dick TP, Keilholz W, Schirle M, Stevanovic S, Dietz K, Heinemeyer W, Groll M, Wolf DH, Huber R, et al. Cleavage motifs of the yeast $20 \mathrm{~S}$ proteasome beta subunits deduced from digests of enolase 1. Proc Natl Acad Sci U S A. 1998;95(21):12504-9.

66. Kisselev AF, Akopian TN, Woo KM, Goldberg AL. The sizes of peptides generated from protein by mammalian 26 and $20 \mathrm{~S}$ proteasomes Implications for understanding the degradative mechanism and antigen presentation. J Biol Chem. 1999;274(6):3363-71.

67. Gelman JS, Sironi J, Berezniuk I, Dasgupta S, Castro LM, Gozzo FC, Ferro ES, Fricker LD. Alterations of the intracellular peptidome in response to the proteasome inhibitor bortezomib. PloS one. 2013:8(1):e53263.

68. Fricker LD. Analysis of mouse brain peptides using mass spectrometrybased peptidomics: implications for novel functions ranging from nonclassical neuropeptides to microproteins. Mol Biosyst. 2010;6(8):1355-65.

69. Parker BL, Burchfield JG, Clayton D, Geddes TA, Payne RJ, Kiens B, Wojtaszewski JFP, Richter EA, James DE. Multiplexed Temporal Quantification of the Exercise-regulated Plasma Peptidome. Mol Cell Proteomics. 2017;16(12):2055-68.

70. D'Archivio AA, Ruggieri F, Mazzeo P, Tettamanti E. Modelling of retention of pesticides in reversed-phase high-performance liquid chromatography: quantitative structure-retention relationships based on solute quantum-chemical descriptors and experimental (solvatochromic and spin-probe) mobile phase descriptors. Anal Chim Acta. 2007:593(2):140-51.

71. Brand GD, Magalhaes MT, Tinoco ML, Aragao FJ, Nicoli J, Kelly SM, Cooper A, Bloch C Jr. Probing protein sequences as sources for encrypted antimicrobial peptides. PloS one. 2012;7(9):e45848.

72. Wang YW, Gao YH, Yao XJ, Liu MC, Hu ZD, Fan BT. Studies on quantitative structure-retention relationships for sulfides on stationary phases of different polarities. Se Pu. 2002;20(5):415-8.

73. Seo JK, Lee MJ, Go HJ, Kim YJ, Park NG. Antimicrobial function of the GAPDH-related antimicrobial peptide in the skin of skipjack tuna, Katsuwonus pelamis. Fish Shellfish Immunol. 2014;36(2):571-81.

74. Branco P, Francisco D, Chambon C, Hebraud M, Arneborg N, Almeida MG, Caldeira J, Albergaria H. Identification of novel GAPDH-derived antimicrobial peptides secreted by Saccharomyces cerevisiae and involved in wine microbial interactions. Appl Microbiol Biotechnol. 2014;98(2):843-53.

75. Cove DJ, Perroud PF, Charron AJ, McDaniel SF, Khandelwal A, Quatrano RS. The moss Physcomitrella patens: a novel model system for plant development and genomic studies. Cold Spring Harbor protocols. 2009; 2009(2):pdb emo115.

76. Tyanova S, Temu T, Cox J. The MaxQuant computational platform for mass spectrometry-based shotgun proteomics. Nat Protoc. 2016;11(12):2301-19.

77. Tyanova S, Temu T, Sinitcyn P, Carlson A, Hein MY, Geiger T, Mann M, Cox J. The Perseus computational platform for comprehensive analysis of (prote)omics data. Nature methods. 2016;13(9):731-40.

78. Wickham H. ggplot2: Elegant Graphics for Data Analysis. New York: Springer-Verlag Inc; 2009

79. Chen $H$, Boutros PC. VennDiagram: a package for the generation of highlycustomizable Venn and Euler diagrams in R. BMC Bioinf. 2011;12:35.

80. Crooks GE, Hon G, Chandonia JM, Brenner SE. WebLogo: a sequence logo generator. Genome Res. 2004;14(6):1188-90.

81. Wiegand I, Hilpert K, Hancock RE. Agar and broth dilution methods to determine the minimal inhibitory concentration (MIC) of antimicrobial substances. Nat Protoc. 2008;3(2):163-75.

82. Carlucci G, D'Archivio AA, Maggi MA, Mazzeo P, Ruggieri F. Investigation of retention behaviour of non-steroidal anti-inflammatory drugs in highperformance liquid chromatography by using quantitative structureretention relationships. Anal Chim Acta. 2007;601(1):68-76.

83. Klein $\mathrm{P}$, Kanehisa M, DeLisi C. Prediction of protein function from sequence properties. Discriminant analysis of a data base. Biochim Biophys Acta. 1984; 787(3):221-6.

84. Fauchere JL, Charton M, Kier LB, Verloop A, Pliska V. Amino acid side chain parameters for correlation studies in biology and pharmacology. Int J Pept Protein Res. 1988;32(4):269-78. 
85. Zimmerman JM, Eliezer N, Simha R. The characterization of amino acid sequences in proteins by statistical methods. J Theor Biol. 1968;21(2):170-201.

86. Xiao X, Chou KC. Digital coding of amino acids based on hydrophobic index. Protein Pept Lett. 2007:14(9):871-5.

87. Aurora R, Rose GD. Seeking an ancient enzyme in Methanococcus jannaschii using ORF, a program based on predicted secondary structure comparisons. Proc Natl Acad Sci U S A. 1998;95(6):2818-23.

88. Lyu PC, Liff MI, Marky LA, Kallenbach NR. Side chain contributions to the stability of alpha-helical structure in peptides. Science. 1990;250(4981):669-73.

Ready to submit your research? Choose BMC and benefit from:

- fast, convenient online submission

- thorough peer review by experienced researchers in your field

- rapid publication on acceptance

- support for research data, including large and complex data types

- gold Open Access which fosters wider collaboration and increased citations

- maximum visibility for your research: over $100 \mathrm{M}$ website views per year

At BMC, research is always in progress.

Learn more biomedcentral.com/submissions 